\title{
ART THERAPY SEBAGAI UPAYA PENATALAKSANAAN PSIKOGERIATRI DI PANTI WREDA DI KOTA SEMARANG
}

\author{
ART THERAPY AS ONE OF PSYCHO GERIATRIC MANAGEMENT \\ AT NURSING HOMES
}

\author{
${ }^{1)}$ Rita Hadi Widyastuti, ${ }^{2)}$ Nurullya Rachma, ${ }^{3)}$ Elis Hartati, ${ }^{4)}$ Artika Nurrahima, ${ }^{5}$ Muhammad \\ Mu'in, ${ }^{6}$ Megah Andriany \\ 1,2,3,4,5,6) Devisi Keperawatan Jiwa dan Komunitas, Departemen Ilmu Keperawatan \\ Fakultas Kedokteran Universitas Diponegoro Semarang \\ Jln. Prof. Soedarto , SH., Tembalang, Semarang, Jawa Tengah \\ Email : ritahadi@ fk.undip.ac.id
}

\begin{abstract}
ABSTRAK
Jumlah Masalah psikogeriatri semakin meningkat di Indonesia. Penatalaksanaan psikogeriatri yang tidak tepat dapat menimbulkan dampak baik bagi lansia maupun caregiver yang merawatnya. Adapun tujuan dari kegiatan ini adalah (1) menurunkan masalah psikogeriatri khususnya kesepian pada lansia di panti wreda; (2) meningkatkan pengetahuan caregiver dalam melakukan Art therapy sebagai upaya dalam penatalaksanaan psikogeriatri di Panti Wreda; dan (3) meningkatkan ketrampilan caregiver dalam melakukan Art therapy sebagai upaya dalam penatalaksanaan psikogeriatri di Panti Wreda. Metode yang digunakan adalah pelaksanaan Terapi Aktivitas Kelompok (TAK) Art Therapy pada lansia dengan masalah psikogeriatri khususnya kesepian, dan pelatihan dengan metode ceramah dan praktik melakukan TAK Art Therapy. Hasil pengabdian menunjukkan: (1) Kegiatan Terapi Aktivitas Kelompok (TAK) Art Therapy pada lansia dapat menurunkan nilai kesepian dengan rata- rata 4,5 ; (2) Pelatihan dilakukan pada 15 caregiver dengan hasil terjadi peningkatan pengetahuan caregiver dengan mean 7,5; dan (3) peningkatan ketrampilan caregiver dalam penatalaksanaan psikogeriatri dengan mean 8. Terapi Aktivitas Kelompok (TAK) Art Therapy pada lansia dapat dilakukan oleh caregiver sebagai upaya dalam penatalaksanaan psikogeriatri di Panti Wreda.
\end{abstract}

Kata kunci : Lansia, Art Therapy, Psikogeriatri

\section{ABSTRACT}

Number of psycho geriatric problems is increasing in Indonesia. Incorrect psycho geriatric management can have an effect on both the elderly and caregiver. The objectives of this activities are (1) to decrease the problem of psycho geriatric, especially loneliness on elderly at nursing home; (2) to increase caregiver knowledge in performing Art therapy as an effort in the management of psycho geriatric at Panti Wreda; and (3) to improve caregiver skills in performing Art therapy as an effort in the management of psycho geriatric in Panti Wreda. The method used is the implementation of Group Activity Therapy Art Therapy on the elderly with psycho geriatric problems, especially loneliness, and training with lecture method and practice doing TAK Art Therapy. The results of activities indicate : (1) Group Activity Therapy Activities Art Therapy in elderly can decrease loneliness value by an average of 4.5; (2) The training was carried out on 15 caregivers with the result of increased caregiver knowledge with mean 7.5 ; and (3) incresing caregiver skill in psycho geriatric management with mean 8. Group Activity Therapy Art Therapy on elderly can be done by caregiver as an effort in psycho geriatric management in Panti Wreda.

Keywords: Elderly, Art Therapy, Psycho Geriatrics

$$
\text { Submitted : } 19 \text { Februari } 2018 \text { Revision: } 16 \text { April } 2018 \quad \text { Accepted : } 25 \text { Juni } 2018
$$


Rita Hadi W, Nurullya Rachma, Elis Hartati, Artika Nurrahima, Muhammad Mu'in, Megah Andriany

Art Therapy Sebagai Upaya Penatalaksanaan Psikogeriatri Di Panti Wreda Di Kota Semarang

PENDAHULUAN

Populasi penduduk lanjut usia (lansia) di Indonesia saat ini khususnya yang berusia diatas 60 tahun mengalami perkembangan yang sangat pesat. Pada tahun 2025 jumlah lansia yang ada di Indonesia diperkirakan mencapai $13,2 \%$ dan menjadi $25,5 \%$ pada tahun 2050 (BPS, 2015). Hal ini merupakan suatu angka yang tinggi yang menunjukkan besarnya jumlah populasi Lansia di Indonesia. Semua orang akan mengalami masa tua atau lansia yang secara alami tidak dapat dihindarkan. Pada proses penuaan akan menimbulkan perubahan degeneratif pada sel yang dapat mempengaruhi fungsi dan kemampuan sistem tubuh. Kondisi penuaan akan menimbulkan berbagai perubahan pada masalah kesehatan pada populasi lansia baik masalah fisik maupun masalah psikologis (Miller, 2004).

Masalah psikologis pada lansia dapat ditemukan pada lansia yang tinggal bersama keluarga ataupun tidak yang tinggal di masyarakat, di fasilitas pelayanan primer maupun pelayanan rawat inap. Jumlah lansia yang mengalami masalah gangguan jiwa yaitu $12 \%$ pada lansia yang tinggal di komunitas, $30 \%$ pada lansia di fasilitas pelayanan primer maupun pelayanan rawat inap dan $70 \%$ pada lansia yang tinggal di unit pelayanan sosial lanjut usia seperti panti wreda ( Riskesdas, 2007 \& Riskesdas, 2013).

Keadaan ini menimbulkan munculnya banyak Institusi yang diperuntukkan untuk menampung orang-orang lanjut usia yang memerlukan, khususnya Lansia yang betul betul tidak mempunyai sanak keluarga atau teman yang bersedia menerima mereka. Panti Wreda sebagai salah satu sarana pelayanan perawatan bagi para Lansia mempunyai peranan dalam mempertahankan status kesehatan Lansia.
Lansia yang tinggal di Panti Wreda Harapan Ibu, Ngaliyan mempunyai masalah kesehatan baik fisik maupun psikologis. Hasil deteksi dini pada lansia didapatkan 20 lansia mengalami masalah depresi dan kesepian, 10 lansia mengalami gangguan kognitif sedang berat dan 1 lansia dengan perilaku kekerasan dan halusinasi. Kondisi ini menimbulkan masalah psikogeriatri yang harus dirawat oleh caregiver di Panti Wreda Harapan Ibu, Ngaliyan. Saat ini lansia dengan masalah psikogeriatri masih tinggal bersama dengan lansia yang lain sehingga dapat menimbulkan masalah dalam wisma, karena belum memiliki ruangan khusus. Masalah yang muncul pada wisma akibat adanya lansia dengan masalah psikogeriatri adalah pertengkaran pada lansia dengan gangguan jiwa yang cenderung melakukan perilaku kekerasan dan keributan pada lansia yang memiliki masalah halusinasi.

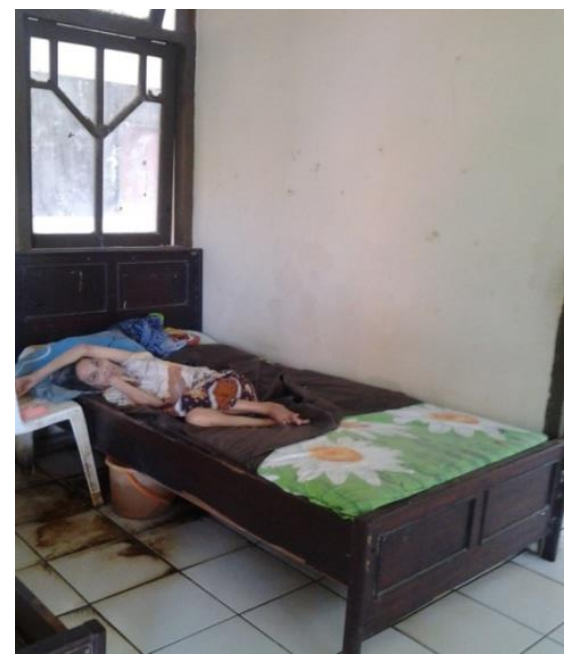

Gambar 1. Lansia dengan masalah psikogeriatri di Panti Wreda Harapan Ibu, Ngaliyan

Lansia yang tinggal di Bapelsos Lansia Pucang Gading, Semarang mempunyai masalah kesehatan baik fisik maupun psikologis. Hasil deteksi dini pada lansia didapatkan 20 lansia mengalami masalah kesepian dan 27 lansia mengalami gangguan 
kognitif sedang - berat. Kondisi ini menimbulkan masalah psikogeriatri yang harus dirawat oleh caregiver di Bapelsos Lansia Pucang Gading, Semarang. Saat ini lansia dengan masalah psikogeriatri diletakkan di wisma khusus tetapi ada beberapa yang tinggal bersama dengan lansia yang lain sehingga dapat menimbulkan masalah dalam wisma, misalnya pertengkaran pada lansia dengan gangguan jiwa yang cenderung melakukan perilaku kekerasan. Lansia dengan psikogeriatri hanya dipenuhi untuk kebutuhan fisik seperti makan, minum dan kebersihan diri. Untuk kebutuhan psikologis belum terpenuhi secara maksimal, misalnya lansia dengan masalah halusinasi hanya ditempatkan pada kamar khusus yang di kunci. Lansia dengan gangguan jiwa hanya melakukan rawat jalan di Rumah Sakit Jiwa, karena keterbatasan kapasitas rumah sakit maka untuk perawatan selanjutnya dilakukan di Bapelsos Lansia.

Hasil wawancara dengan caregiver didapatkan kendala pertama yang dihadapi oleh caregiver di Panti Wreda adalah dalam perawatan lansia dengan psikogeriatri adalah kesulitan dalam memberikan penatalaksanaan menyeluruh karena belum ada caregiver yang memiliki pengetahuan dan ketrampilan mengenai penatalaksanaan lansia dengan psikogeriatri .

Kendala kedua yaitu lansia yang mengalami gangguan psikogeriatri juga mengalami gangguan mobilisasi sehingga tidak bisa mengikuti kegiatan di ruang rekreasi. Panti belum memiliki sarana dan prasarana yang menunjang untuk melakukan terapi pada lansia dengan masalah psikogeriatri misalnya belum ada alat-alat untuk art therapy pada lansia. Belum ada kegiatan terapi aktivitas kelompok bagi lansia yang mengalami masalah psikogeriatri yang disertai dengan masalah gangguan mobilisasi.
Kendala ketiga adalah perbandingan jumlah caregiver dengan jumlah lansia yang tidak sesuai yaitu 1 caregiver : 4 lansia dan belum adanya panduan yang baku yang dapat memudahkan caregiver untuk dapat melakukan perawatan lansia dengan masalah psikogeriatri secara efisien dan terstruktur.

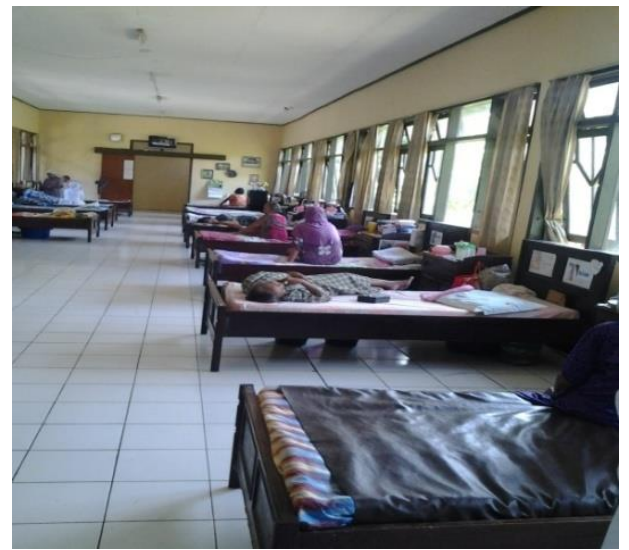

Gambar 2. Kondisi ruang lansia di panti wreda

Tujuan dari kegiatan pengabdian sesuai dengan kondisi Panti Wreda Harapan Ibu, Ngaliyan dan Bapelsos Lansia Pucang Gading, Semarang adalah (1) menurunkan masalah psikogeriatri khususnya kesepian pada lansia di panti wreda; (2) meningkatkan pengetahuan caregiver dalam melakukan Art therapy sebagai upaya dalam penatalaksanaan psikogeriatri di Panti Wreda; (3) meningkatkan ketrampilan caregiver dalam melakukan Art therapy sebagai upaya dalam penatalaksanaan psikogeriatri di Panti Wreda.

\section{METODE KEGIATAN}

Kegiatan Art therapy sebagai upaya dalam penatalaksanaan psikogeriatri di Panti Wreda bermitra dengan Panti Wreda harapan Ibu, Ngaliyan dan Bapelsos Lansia Pucang Gading. Panti Wreda Harapan Ibu, Ngaliyan memiliki 10 orang caregiver sedangkan 
Rita Hadi W, Nurullya Rachma, Elis Hartati, Artika Nurrahima, Muhammad Mu'in, Megah Andriany

Art Therapy Sebagai Upaya Penatalaksanaan Psikogeriatri Di Panti Wreda Di Kota Semarang

Bapelsos Lansia Pucang Gading memiliki 38 orang caregiver.

Kegiatan pengabdian dilakukan dengan tahapan ; 1) Pelaksanaan terapi aktivitas kelompok (TAK) Art Therapy pada lansia dengan psikogeriatri dengan masalah kesepian; 2) pelatihan pelaksanaan TAK Art Therapy pada caregiver; dan 3) pembuatan buku panduan dalam melaksanakan TAK Art Therapy di Panti Wreda harapan Ibu, Ngaliyan maupun Bapelsos Lansia Pucang Gading.

Kegiatan terapi aktivitas kelompok (TAK) Art Therapy dilakukan pada lansia yang mengalami masalah psikogeriatri kesepian. Sebelum dan setelah kegiatan TAK Art Therapy lansia dilakukan pengukuran nilai kesepian dengan menggunakan instrumen UCLA Loneliness scale.

Metode pelatihan dilakukan dengan ceramah, tanya jawab, demonstrasi dan redemonstrasi oleh pihak caregiver serta praktik langsung pada lansia. Kegiatan pelatihan dilakukan dengen metode ceramah yang berisi tentang Mengenal demensia, Komunikasi pada lansia, Kesepian, Penatalaksanaan menjelang ajal, terapi aktivitas kelompok Art therapy pada lansia bagi lansia dengan masalah kesepian. Metode evaluasi untuk mengukur peningkatan pengetahuan caregiver dilaksanakan dengan pemberian soal sebelum dan sesudah pelaksaaan pelatihan (pre-post test). Kegiatan pelatihan juga dilakukan demostrasi tentang cara melakukan TAK Art Therapy lansia dengan masalah kesepian. Selanjutnya caregiver melakukan redemonstrasi oleh pihak caregiver serta praktik langsung pelaksanaan TAK Art Therapy pada lansia. Metode evaluasi untuk mengukur peningkatan ketrampilan caregiver dilaksanakan dengan mengukur ketrampilan caregiver sebelum dan setelah pelatihan dengan menggunakan lembar observasi yang berisi tentang standar operasional prosedur (SOP) pelaksanaan TAK Art Therapy.

\section{HASIL DAN PEMBAHASAN}

Hasil dari kegiatan pengabdian masyarakat ini adalah :

1. Penurunan nilai kesepian pada lansia setelah dilakukan TAK art therapy.

Kegiatan TAK Art therapy pada lansia di Panti Wreda Harapan Ibu selama 5 hari berturut turut dapat menurunkan nilai kesepian dengan rata-rata 4,5. Terapi Aktivitas Kelompok (TAK) merupakan kegiatan yang diberikan kelompok klien dengan maksud memberi terapi bagi anggotanya (Stuart \& Sundeen, 1998). The American Art Therapy Association (AATA) mendefinisikan art therapy sebagai kegiatan yang dilakukan pada klien dengan masalah mental dengan menggunakan media yang artristik, dengan proses yang kreatif dan menghasilkan suatu kerajinan seni untuk mengeksplorasi perasaan, meningkatkan kesadaran diri, mengelola perilaku dan meningkatkan ketrampilan sosial, meningkatkan orientasi dan menurunkan kecemasan (American Art Therapy Association, 2014). Art Therapy adalah gabungan pendekatan psikoterapi dengan berdasarkan pada mind body, pada kegiatan ini klien lebih mampu untuk dapat mengekspresikan perasaan melalui sensori maupun kinestetik ( Im, 2014). Art therapy juga bisa berdampak untuk meningkatkan kesehatan lansia dengan mengurangi emosi negatif, meningkatkan konsep diri dan menurunkan kecemasan (Kim, 2013). 
Rita Hadi W, Nurullya Rachma, Elis Hartati, Artika Nurrahima, Muhammad Mu'in, Megah Andriany

Art Therapy Sebagai Upaya Penatalaksanaan Psikogeriatri Di Panti Wreda Di Kota Semarang

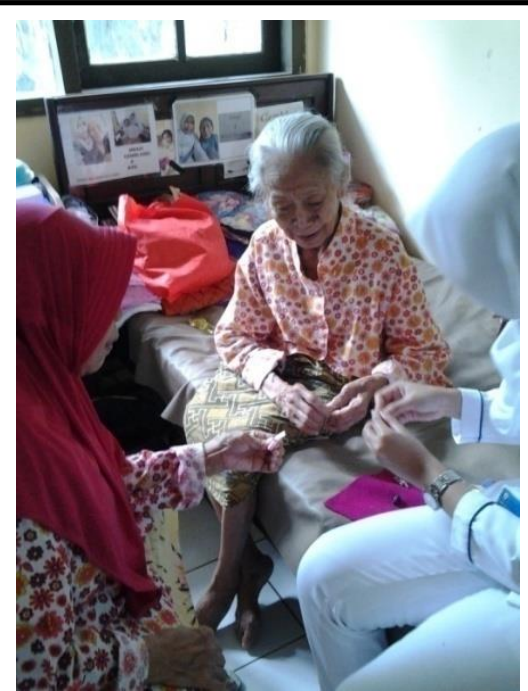

Gambar 3. Pelaksanaan TAK pada lansia yang mengalami masalah kesepian

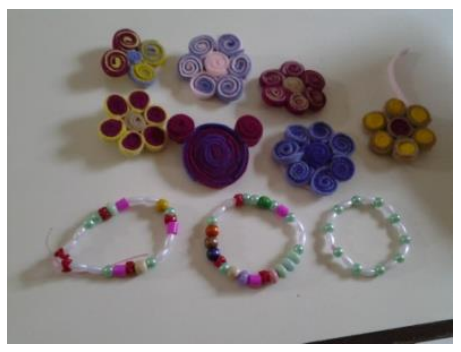

Gambar 4. Hasil yang telah di buat kerajinan tangan saat TAK

2. Peningkatan pengetahuan dalam melakukan Art therapy sebagai upaya dalam penatalaksanaan psikogeriatri di Panti Wreda

Pelatihan pelaksanaan TAK Art Therapy pada caregiver yang meliputi pemberian materi tentang Mengenal demensia, Komunikasi pada lansia, Kesepian, Penatalaksanaan menjelang ajal, terapi aktivitas kelompok Art therapy pada lansia bagi lansia dengan masalah kesepian. Metode pelatihan dilakukan dengan ceramah, tanya jawab. Pelatihan yang dilakukan pada 15 caregiver dengan hasil terjadi peningkatan pengetahuan caregiver dengan mean 7,5.

Metode evaluasi untuk mengukur peningkatan kognitif caregiver dilaksanakan dengan pemberian soal sebelum dan sesudah pelaksaaan pelatihan (pre-post test). Sikula dalam Sumantri (2000) mengartikan pelatihan sebagai: "proses pendidikan jangka pendek yang menggunakan cara dan prosedur yang sistematis dan terorganisir. Para peserta pelatihan akan mempelajari pengetahuan dan keterampilan yang sifatnya praktis untuk tujuan tertentu. Pelatihan adalah suatu kegiatan untuk meningkatkan kinerja saat ini dan kinerja mendatang (Veithzal Rifai: 2004).

3. Peningkatan ketrampilan dalam melakukan Art therapy sebagai upaya dalam penatalaksanaan psikogeriatri di Panti Wreda

Pelatihan pelaksanaan TAK Art Therapy pada caregiver juga dilakukan praktik tentang terapi aktivitas kelompok pada lansia dan Art therapy bagi lansia dengan masalah kesepian. demonstrasi dan redemonstrasi oleh pihak caregiver serta praktik langsung pada lansia. Pelatihan yang dilakukan pada 15 caregiver dengan hasil terjadi peningkatan ketrampilan caregiver dalam penatalaksanaan psikogeriatri dengan mean 8 .

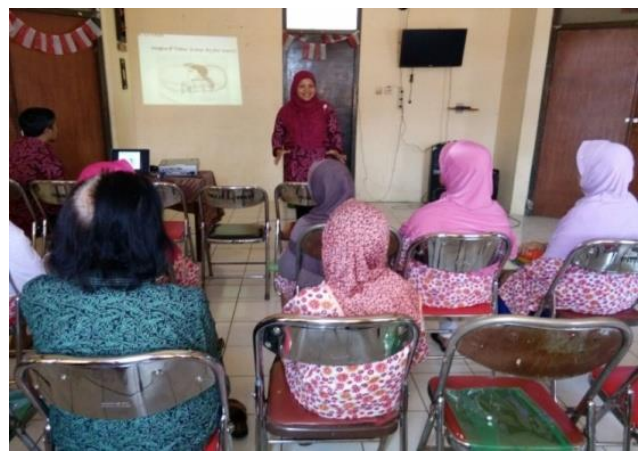

Gambar 5. Pelatihan caregiver 
Rita Hadi W, Nurullya Rachma, Elis Hartati, Artika Nurrahima, Muhammad Mu'in, Megah Andriany

Art Therapy Sebagai Upaya Penatalaksanaan Psikogeriatri Di Panti Wreda Di Kota Semarang

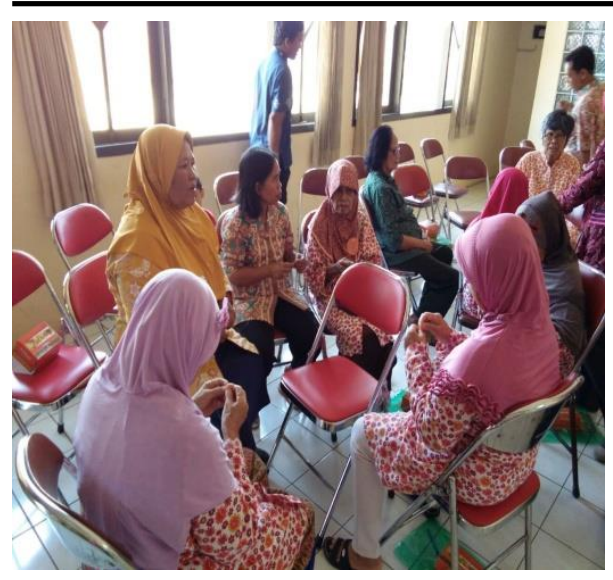

Gambar 6. Praktik oleh caregiver dalam melakukan TAK art therapy pada lansia dengan masalah psikogeriatri

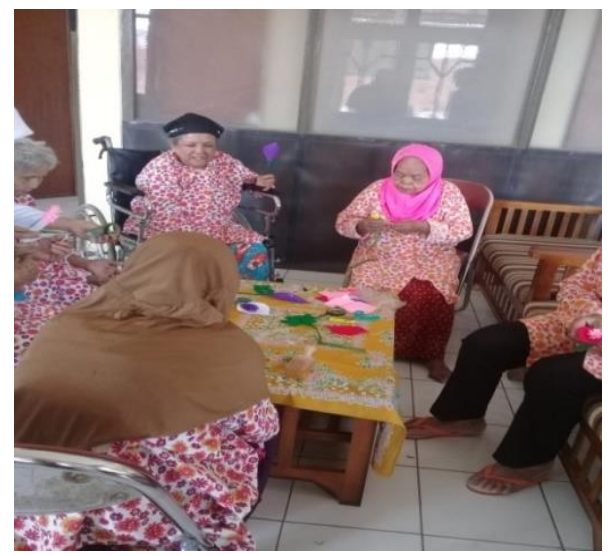

Gambar 7. Praktik oleh caregiver dalam melakukan TAK art therapy pada lansia dengan masalah psikogeriatri

Dessler dalam Sirait (2006) menyatakan bahwa pelatihan memberikan pegawai baru atau yang ada sekarang ketrampilan yang mereka butuhkan untuk melaksanakan pekerjaan.

\section{SIMPULAN}

Hasil pengabdian dapat menurunkan masalah psikogeriatri khususnya kejadian kesepian pada lansia. Kegiatan ini juga meningkatkan pengetahuan dan ketrampilan caregiver dalam melakukan TAK Art therapy. Pelaksanaan TAK Art therapy dapat dilakukan secara rutin oleh lansia dan caregiver sebagai alternatif dalam penatalaksanaan lansia dengan kesepian dengan menggunakan peralatan art therapy. Diperlukan tindak lanjut untuk memonitoring hasil pelatihan, misalnya dengan melakukan sarasehan atau diskusi secara berkelanjutan dengan para caregiver dalam penatalaksanaan psikogeriatri.

\section{DAFTAR PUSTAKA}

American Art Therapy Association. (2014). Definition statement. http://www.arttherapy.org

Badan Pusat Statistik. (2015). Statistik Penduduk Lanjut Usia 2015. http://www.bps.go.id.

Im, M. L., \& Lee, J. I. (2014). Effects of art and music therapy on depression and cognitive function of the elderly. Technology and Health Care, 22(3), 453-458.

Kim, S. K. (2013). A randomized, controlled study of the effects of art therapy on older Korean-Americans' healthy aging. The Arts in Psychotherapy, 40(1): 158164.

Miller, C.A. (4th edition). (2004). Nursing for wellness in Older adult: Theory and Practice.. Philadelphia: Lippincott Williams and Wilkins.

RISKESDAS. (2007). Hasil RISKESDAS 2007. www.depkes.go.id

RISKESDAS. (2013). Hasil RISKESDAS 2013. www.depkes.go.id 
Rita Hadi W, Nurullya Rachma, Elis Hartati, Artika Nurrahima, Muhammad Mu'in, Megah Andriany Art Therapy Sebagai Upaya Penatalaksanaan Psikogeriatri Di Panti Wreda Di Kota Semarang

Sirait, J.T., (2006). Memahami Aspekaspek Pengelolaan Sumber Daya Manusia Dalam Organisasi,. Jakarta. Grasindo.

Sumantri, S. (2000), Pelatihan dan Pengembangan Sumber Daya Manusia, Bandung, Fakultas Psikologi Unpad.

Stuart, G. W., Sundeen, JS., (edisi III). (1998). Keperawatan jiwa (Terjemahan), alih bahasa: Achir Yani Jakarta : EGC.

Veithzal Rivai,. (2004). Manajemen Sumber Daya Manusia Untuk Perusahaan, Jakarta, PT. Raja Grafindo Persada 